\title{
Structured Problem-Solving: AgAinst THE 'STEP-BY-STEP' METHOD
}

\author{
GREG TAYLOR*
}

[Recently a German professor has advocated the adoption in this country of the German style of legal problem solving. Occasionally a German author attempts to civilise the common-law world using what is put forward as a more rational approach. But with such endeavours is usually associated a certain lack of self-critical reflection. In this instance an Australian author is able to draw on his studies in Germany to rectify the omission. He shows that the problem-solving method in question conveys a false picture of the nature of legal problem solving and of the law itself, while not possessing the advantages claimed for it.]

\section{INTRODUCTION}

Recently, Professor ${ }^{1}$ Lutz-Christian Wolff, currently of the City University of Hong Kong but qualified as a professor (according to the extremely demanding German requirements) in Passau, Germany, wrote in praise of the German problem-solving method. ${ }^{2}$ In his article, he referred to that method (as will I) as the 'step-by-step' method ${ }^{3}$ and explained its principal features well. Wolff's article provides me, however, with a welcome opportunity to

\footnotetext{
* Senior Lecturer, Faculty of Law, Monash University. The author wishes to thank Cornelia Koch, Professor Dr Lothar Kuhlen, Professor Horst Lücke, Dr Sabine Pittrof and Roland Raudies for their very useful criticisms of and suggestions on a draft of this piece. The views expressed here are, however, the author's own.

${ }^{1}$ Professor Wolff is an außerplanmäßiger Professor at the University of Passau and accordingly entitled to the full professorial title.

${ }^{2}$ Lutz-Christian Wolff, Structured Problem Solving: German Methodology from a Comparative Perspective 14 Legal Education Review 19 (2004).

${ }^{3}$ Although that is not its German name. It is referred to there as the Gutachtenstil, the 'opinion style' - 'opinion' in the non-American sense contrasted, not equated, with Court judgments.
} 
write a short 'counterblast' based on my reflections on that method informed by my experiences as a law student in Germany when I was required to use that method in examinations - even if it must by necessity appear elsewhere, as the journal in which he published does not make a practice of publishing replies. I will argue, first, that the 'step-by-step' method does not possess the virtues which Wolff claims for it and, secondly, that, while it has one or two other virtues, it is in the final analysis a positively harmful method of problem solving.

I cannot, of course, repeat here the detailed analysis of the 'step-by-step' method that Wolff puts forward. Those seeking full information about it should read his article. In summary, however, it involves (in civil law matters) the identification of the basis of a possible claim by the plaintiff, and then a listing of all the preconditions for making the claim together with an analysis of whether the legal prerequisites for the satisfaction of that claim have been fulfilled. This must, furthermore, be done in such a way that the answer does not appear until the end so that it appears that the answer emerges as the analysis progresses and is a result of applying the law to the facts rather than, perhaps, of instinct or prejudice divorced from the precise content of the law. It is a syllogistic style, or rather a style involving a series of syllogisms, in which the major premise is always a proposition of law, the minor premise a statement about the facts and their relation to the proposition of law in the major premise, and the conclusion a statement about whether the claim does or does not succeed.

Wolff gives an example of problem solving using the method he advocates at pp. $30-32$ of his article. Because of its length, it cannot be reproduced here. In brief, it involves a contract between $\mathrm{A}$ and $\mathrm{B}$ for the sale of a painting called 'Green Frog' by A to B. A then assigns his rights under the contract to $\mathrm{C}$, and advises $\mathrm{B}$ of that. $\mathrm{C}$ now wishes to enforce the contract against $\mathrm{B}$. We are first asked, however, whether A has any remaining rights to enforce the contract against B. The answer to this is quite simple: no, because he has assigned them. Under the 'step-by-step' method, however, this cannot be simply stated; this is how it has to be solved:

A could have lost his claim against B by way of assignment to C. Precondition for the effectiveness of such assignment would be that an assignment agreement has been concluded between $\mathrm{A}$ and $\mathrm{C}$, Article 398 of the German Civil Code. On 15 December A and C have agreed that all of A's rights and claims arising out of the 'Green Frog' 
contract shall be transferred to $\mathrm{C}$. Therefore, they have concluded a valid assignment agreement. A has lost his claim against B to $\mathrm{C} .{ }^{4}$

The correct 'step-by-step' structure is followed here. There is a statement of the legal form in which the problem presents itself in the first sentence, always in the conditional form ('could') as we are not allowed to give away the answer until we have gone through the process prescribed by the method. Then the second sentence states the abstract proposition of law that governs the area. The third sentence is the minor premise, an extract from the facts that is relevant to applying the proposition of law in the major premise. Finally, there is the conclusion about the legal consequence that follows.

The above is only a short extract from Wolff's solution; the full solution to the 'Green Frog' problem involves a series of analyses on the pattern of that just quoted in order to deal with various aspects of the problem, such as whether the claim has been extinguished by lapse of time, whether indeed it existed in the first place and so on. Then the process has to be repeated for C's claim against B, for so far we have been dealing only with A's!

The style advocated by Wolff is not, in its German home, merely a scheme to be used in planning examination answers or identifying the issues raised by problems. Nor is it just one way, or even merely the dominant way, of structuring students' answers to problems in law examinations. It is, rather, the one and only approved way of answering examination problems. Every student must use the style outlined by Wolff in examination answers. A student who does not do so will fail, and even minor lapses from the approved style will lead to rude comments in the margin by the marker and to possible loss of marks. Although his article is not entirely unambiguous on this point, I take it that Wolff is advocating that the 'step-by-step' method should be adopted in the same capacity as it is in Germany: as the one and only approved means of answering examination problems. If it is to have that function, it had better be pretty good. My case will however be that, while it has some minor virtues, they are greatly outweighed by its defects. It should be considered, at most, a help for those who find it useful, not a compulsory structure to be used by everyone.

${ }^{4}$ See Wolff, above n 2, 30. 


\section{VIRTUES OF THE METHOD}

What then are the virtues of the 'step-by-step' method? Somewhat surprisingly, in my view, Wolff claims that the chief virtue of the 'step-bystep' method is the stereotypically Teutonic virtue of efficiency. Indeed, he praises the 'step-by-step' method at some length for its efficiency, claiming that efficiency is "the sole criterion" ${ }^{5}$ by which approaches to problem solving should be assessed, and that the "step-by-step' method "embodies efficiency" because it requires "a minimum input of resources". Accordingly, "[n]o more efficient way of problem solving is available". ${ }^{6}$ This confirms Wolff's rather Panglossian view that '[t]he general adoption of a specific method' - for his method is indeed generally adopted in German law schools - "seems to indicate that this method is better than others'?

Let us therefore take the example Wolff gives and measure it against the criterion he sets up. An example of problem solving according to the 'stepby-step' method used in German law schools may be found at pages 30-32 of his article. It will be seen at once by anyone who takes the trouble to read it that the problem-solving method advocated by Wolff requires a considerable waste of time and ink dealing with non-issues. This is because it requires the problem-solver to deal, step by step, with every single requirement for the creation of a valid contract and the assignment of obligations under it, even those that are not in the least doubtful. And, because there are two possible plaintiffs (A and $\mathrm{C}$ in his example), this has to be done not once, but twice.

Thus, it is quite clear on the facts given in his example that A once had a contract with $\mathrm{B}$, but has validly assigned it to $\mathrm{C}$. The question is whether the non-performance by $\mathrm{C}$ of what were originally A's obligations relieves $\mathrm{B}$ from performing his side of the bargain. But, under the 'step-by-step' method, this cannot simply be stated. It must be laboriously proved by means of showing that the requirements for the valid creation of the original contract were met (1 (b) in his example), followed by a demonstration that the assignment is valid (1 (c) - this is the extract quoted above). The process has then to be repeated for C's possible claim against B (2 (b)). In 2 (c), the obvious fact that $\mathrm{C}$ has not done anything to extinguish his claim must be specially mentioned; there is not the remotest indication in the facts that $\mathrm{C}$ has done anything which could lead to the extinguishment of the claim, but if he had then of course he would have no claim, so that this negative

\footnotetext{
${ }^{5}$ Ibid 33.

${ }^{6}$ Ibid 34.

${ }^{7}$ Ibid 33.
} 
precondition to a successful claim by $\mathrm{C}$ cannot simply be passed over in silence, or else an essential step in the reasoning will have been missed. At last, under 2 (d), the real heart of the issue is reached: whether B is entitled to refuse performance until the assignee delivers. It is then concluded, with the degree of prolixity to which we are by now accustomed, that this is so. A simple problem which could have been solved in two or three lines - which concerned the ability to plead a contractual defence against an assignee as well as the assignor - has been turned into a novel because of the need, under the 'step-by-step' procedure, to show that one has checked every single requirement for the creation and enforceability of the claim, even those that are not controversial.

This has to be done separately, as Wolff points out, not merely for each possible plaintiff, but for each possible claim of each possible plaintiff. Thus, if there are claims for damages and payment of the purchase price, the process has to be repeated separately for each, as "the preconditions for the payment of damages and for the payment of the purchase price may not be the same, and therefore a joint examination may cause confusion". ${ }^{8}$ But, we may respond, they are nearly the same; it is a question of remedy only; and surely we are not so easily confused that we cannot deal with two remedies available to the one plaintiff at the one time (just as we also generally manage to walk and chew gum simultaneously).

Could this lengthy procedure have some other advantage to recommend it? One German author says that an answer written using the 'step-by-step' method:

[I]s to be written, as a rule, for someone who does not know the legal position, but needs to discover why the relevant legal question must be answered in the way suggested by the writer. The answer must therefore be understandable on its own even for a layperson who knows only the facts and the text of the law. ${ }^{9}$

It has accordingly been suggested to $\mathrm{me}^{10}$ that the 'step-by-step' method might assist future lawyers to hone their communication skills with the lay public who will later be their clients and require the reasoning behind the lawyer's answer to a legal problem to be explained to them. But such skills

\footnotetext{
${ }^{8}$ Ibid 24.

${ }^{9}$ Gerhard Wolf, Bemerkungen zum Gutachtenstil [1996] Juristische Schulung 30, $33 \mathrm{f}$.

${ }^{10}$ By Cornelia Koch. See below n 11.
} 
are not well taught by means of requiring them to be practised in examinations on the substantive law. Communication with clients is much more than, and very different from, just taking them through the steps involved in concluding that the law produces a particular result in their case. Apart from that alleged advantage, there is no reason at all to proceed as if one were explaining the answer to a layperson.

As Wolff's example shows, if the 'step-by-step' method has a virtue, it is not efficiency - for the reasons given, it is one of the most egregiously inefficient methods for answering questions that could possibly be devised - but the equally stereotypically Teutonic virtue of thoroughness. The advantages of thoroughness are not to be underestimated, especially for students, such as those in their first years of law, who might otherwise overlook a particular issue. The question is whether this virtue is purchased at too high a cost. It is my case that it is.

First, of course, thoroughness is a doubled-edged sword. A problem-solving method that may help first-year students to ensure that they do not miss anything important is not necessarily appropriate for later-year students who, one might hope, have managed to get over the teething problems of the first couple of weeks of law studies. ${ }^{11}$ On the other hand, the 'step-by-step' method does not - no method could - absolutely guarantee that nothing will be missed out: it is always possible that a student will entirely fail to see that a problem raises a particular type of legal norm, or legal institution (such as unjust enrichment as well as contract) or defence (such as expiry of the limitation period) and thus fail to consider the issue concerned. So we should not overestimate the extent to which the 'step-by-step' method promotes the virtue of thoroughness. The great waste of time and effort which it requires in the consideration of things which are not controversial also means that students may run out of time, panic and forget something, or simply not have time to reach the real issues in the case after dealing with the non-issues.

\footnotetext{
${ }^{11}$ Cornelia Koch acutely observes (in an e-mail to me) that my view that the problem-solving method might aid first-year students, but is unsuitable for later-year students, is really seen in an Australian context. In Australia, she continues, problems do not become much more complex from first to final year. Only the area of law changes. Students are rarely required to make connections between different subject areas. In Germany, on the other hand, problems become a lot more complex as the students progress (as there is a state-run examination at the end of studies on all areas of law) and, therefore, a method like that advocated by Wolff is a suitable aid to deal with such problems. This may well be something in this, but of course this view, if accurate, does not make the 'step-by-step' method more suitable for Australian conditions.
} 
It may be, as Wolff claims to know from anecdotal evidence, that 'commonlaw lawyers normally confirm that the 'step-by-step' method is exactly how they would approach the legal analysis of a private-law problem'. ${ }^{12}$ Possibly this is often so, both for academics and for practising lawyers. Having some acquaintance with the German gift for systematic, thorough and wellstructured legal thinking, I can say that it has certainly helped me as an academic. Nor have I any wish to advocate that students should not attempt to write well-structured examination answers. Practitioners no doubt try to proceed step-by-step as well. A barrister asked to advise, for example, on a question of frustration in contract law would, one might hope, first check that there was in fact a valid contract in the first place. The barrister would be expected to ensure that there was consideration, no vitiating factors, no breaches of the Statute of Frauds, and so on. But the 'step-by-step' method goes well beyond merely providing a general structure for examination answers or opinions, or reminding us to proceed in a logical order. A barrister might well use something like a 'step-by-step' approach in deciding what the issues are in the case, but would not burden his or her actual opinion with an elaborate demonstration that the contract is valid and enforceable if, having carried out these basic checks, there is no real issue about any of them; still less would a barrister use in an opinion the highly manneristic formula of the 'step-by-step' method which Wolff reproduces in his article. Nor should a student be expected to deal at length, or at all, with non-issues. The 'step-bystep' method, in other words, elevates a handy checklist procedure, useful in planning one's answer to a problem and deciding what the real issues are, far beyond its station.

So the virtues of the 'step-by-step' method are partly chimerical, and partly exaggerated. I will now consider the disadvantages of the 'step-by-step' method.

\section{Disadvantages of the Method}

First, the 'step-by-step' - at least in its German home, and in the form advocated by Wolff - places far too much emphasis on questions of form rather than content. The chief reason for this is that, as Wolff points out, ${ }^{13}$ it proceeds on the assumption that the writer starts with an open mind about the outcome and proceeds through the relevant legal requirements, considering whether each is satisfied, until a conclusion can be reached, and that the

\footnotetext{
${ }^{12}$ See Wolff, above n 2, 49.

${ }^{13}$ Ibid 28.
} 
conclusion is not known until the end of the analysis. ${ }^{14}$ Thus, any language that appears to suggest that the problem-solver might know the outcome before the end is reached must be avoided. Thus, as Wolff points out:

[T] he legal analysis of a problem can never start out with the final result. On the contrary, the final result must be developed step-by-step. German legal education emphasises that the language used by law students should reflect such step-by-step verification of an initial hypothesis by using the conditional form. ${ }^{15}$

As an empirical proposition, the assumption that the result is never known until the end of legal analysis is, of course, entirely false. Better law students will be able to develop an instinct for the solution to many legal problems before even putting pen to paper. Not only is the assumption false as a matter of fact; it would be undesirable if students proceeded in that way. We should encourage students to work out the solution to which they will come before they start writing, as that will lead to better planned answers, rather than let them think that they should start writing first and come up with the solution as they go along.

Even leaving aside, however, the empirical falsity and pedagogical undesirability of its starting point, the 'step-by-step' method also requires students to use a prescribed structure and form of language reflecting the hypothesis that they do not know the answer until the end. This applies to the answer to the question as a whole, but also to each sub-issue within the problem (even the uncontroversial ones). What this looks like can be seen, in English translation, in Wolff's example at pp 30-32 of his article. Part 1 accordingly starts off with the statement that A could have a claim based on a particular paragraph of the Civil Code, and ends with a conclusion that A has no claim; the same procedure is followed in Part 2 for C's claim. Within each part, each sub-heading repeats the process of hypothesising that a particular state of affairs might be true and considering whether it is by means of a more or less syllogistic procedure in which a proposition of law is the major premise and the relevant fact is the minor premise. Only then can a conclusion on each sub-issue be stated.

\footnotetext{
${ }^{14}$ Christian Fahl, Bemerkungen zum Urteilsstil [1996] Juristische Schulung 280, 280; Dieter Schmalz, Methodenlehre für das juristische Studium (4th ed., Nomos, Baden Baden 1998), pp. 156, 158; Wolf, [1996] Juristische Schulung 30, 30.

${ }^{15}$ See Wolff, above n 2, 28.
} 
Heaven forbid that the student should say straight away that 'A clearly concluded a valid contract with $\mathrm{B}$, and has equally clearly assigned his rights under it to C'! This would be 'wrong', because it does not follow the prescribed syllogistic procedure of starting off with a question rather than a conclusion and then stating the law as the major premise and the relevant fact as the minor premise. A student who went straight to the conclusion would find a rude note from the marker in the margin of the script accusing the student of using the style appropriate to Court judgments (when the Judge already knows the answer in advance, according to this peculiar theory, and can write accordingly) rather than to student answers to examination questions (in which the theory is that the answer is not known until the end of the step-by-step analysis).

That being so, a vast quantity of effort has to be devoted by the student to learning this style and then, under the stress of examination conditions, ensuring that it is adhered to. One must always pay attention to ensure that one both adheres to the syllogistic form and also does not slip into the natural habit of betraying the solution to the problem before reaching the very end of the analysis. To assist students not to make an error, books of advice are written about how to comply with the required style. Debates are conducted in learned journals about whether a particular form of language or even particular words ('because' or 'therefore', for example) are suitable for use by students in examination answers, and to what extent short cuts are permissible especially in later-year examinations when the answer to a particular sub-problem is not controversial. ${ }^{16}$ This is a gigantic waste of effort (and the discussion about permissible short-cuts makes one wonder what the point of the whole procedure is anyway if it can be modified in later-year examinations in relation to non-controversial issues). In the end, who cares what words are used?

Admittedly, some students manage all this almost effortlessly - as a student in Germany, I did not find it particularly hard, partly because I was watching my language anyway as a non-native speaker - but others have terrible difficulty with it, and I know people who have withdrawn from law studies partly because of it.

\footnotetext{
${ }^{16}$ See, eg, Fahl, [1996] Juristische Schulung 280, 280; Schmalz, Methodenlehre, p. 156; Wolf, [1996] Juristische Schulung 30, 31.
} 


\section{iv A False Picture of the nature of Legal Problem-Solving}

The most objectionable features of the 'step-by-step' method are not, however, those already mentioned. Nor is it the fact that law students are required to write in a completely uniform style - a requirement which unfairly advantages those who are able to master its peculiarities at the expense of permitting a diversity of styles and approaches suiting a diversity of temperaments. ${ }^{17}$ It is rather the basically incorrect assumptions about the nature of legal thought that the method involves.

It will be seen from Wolff's example that the 'step-by-step' method proceeds by stating, first, that a possible legal consequence might ensue from a set of facts; secondly, by stating what rule governs that consequence; thirdly, applying the rule to the facts; and, finally, reaching a conclusion. This syllogistic procedure is quite appropriate for the sort of problems one might encounter in one's first weeks of law study. We all know the type. In contract law, they are problems along the following lines: 'A sends a letter to B offering to sell A's library for $£ 100$; B posts a letter by return accepting the offer, but before A receives the letter, A sends a telegram retracting the offer. Is there a valid contract?' (A always sends a telegram - rather than an e-mail or an SMS - because the problem has been passed down through the generations and is at least a hundred years old.) The 'step-by-step' method might well be quite appropriate at this stage of one's studies for a number of reasons: the simplicity of the problem and of the rules it involves; the need for practice in the application of rules even to non-controversial facts; and the law student's limited degree of appreciation of the way in which the law works and need for guidance in problem solving. Using something like the 'step-by-step' method in solving what might be called 'kindergarten' problems also helps to take the law student through the concepts of consideration and intention to create legal relations even though they are not of course in question in the problem.

Pretty soon, however, the brighter students realise - and eventually, it might be hoped, everyone realises - that most legal problem-solving is rarely as straightforward as it was in the first Contract tutorial: know the rule, apply it to the facts, get a clear simple answer. Continuing on the voyage through contract law, for example, the student comes to the doctrine of frustration, and immediately faces the problem that the rule itself cannot be stated with any degree of certainty, let alone applied to the facts in a mechanical way.

${ }^{17}$ Bernhard Großfeld, Examensvorbereitung und Jurisprudenz [1992] Juristenzeitung 22, 25-27. 
And it just gets harder as we deal with more difficult subjects such as Torts or Constitutional Law.

The 'step-by-step' method assumes, however, that the process of applying the law to the facts is a simple syllogistic procedure involving stating the applicable rule and then applying the facts to it. This is an assumption which is left over from the eighteenth century (or earlier), ${ }^{18}$ when it was thought possible to state the law with complete exactitude in a code and then simply apply it as cases cropped up ${ }^{19}$ and when Montesquieu wrote that 'the national judges are not more than the mouth that pronounces the words of the law, mere passive beings, incapable of moderating either its force or rigour'. ${ }^{20}$

Because it proceeds by breaking down each legal question into a series of smaller and smaller sub-questions, it is also very strongly reminiscent of the Begriffsjurisprudenz ('conceptual jurisprudence') current in about the same period (and influential in various guises even into the twentieth century) ${ }^{21}$ with its belief in 'a pyramid of concepts structured according to the rules of formal logic'. ${ }^{22}$ As Professor Donald Kommers points out, the style and basic assumptions of Begriffsjurisprudenz differ greatly from those of the common law. The emphasis of Begriffsjurisprudenz is on 'the idea of a Court - an autonomous legal institution - entrusted with the systematic if not the mechanical application of fixed rules of law'. ${ }^{23}$

\footnotetext{
${ }^{18}$ In fact, it may be that the "step-by-step" method goes back to the Roman or mediaeval practice of sending cases to learned lawyers for opinions (Hermann Lange, Das Rechtsgutachten im Wandel der Geschichte [1969] Juristenzeitung 157). In Germany it can be traced, on the written records, back to the 1830s: Filippo Ranieri, 'Stilus Curiae: Zum historischen Hintergrund der Relationstechnik' (1985) 4 Rechtshistorisches Journal 75, 85). It is however certainly older than Wolff might be thought to be implying (see Wolff, above $\mathrm{n} 2,22$ ), as it was definitely in use in the decade after the Second World War (personal discussion with Professor Horst Lücke).

${ }^{19}$ Martin Kriele, Theorie der Rechtsgewinnung, dargestellt am Problem der Verfassungsinterpretation (2 ${ }^{\text {nd }}$ ed; 1976) 60-63.

${ }^{20}$ Charles de Secondat, Baron de Montesquieu, Spirit of the Laws (1751).

${ }^{21}$ See Stanley Paulson, The Theory of Public Law in Germany 1914 - 1945 (2005) 25 Oxford Journal of Legal Studies 525, 528-530, 535-537.

${ }^{22}$ Karl Larenz, Methodenlehre der Rechtswissenschaft (1991), p. 21; see also at 2124; Ranieri, Rechtshistorisches Journal 4 (1985), 75, 77. An interesting and perceptive overview may be found in Stefan Vogenauer, An Empire of Light? Learning and Lawmaking in the History of German Law [2005] Cambridge Law Journal 481, 485-500.

${ }^{23}$ Donald Kommers, The Constitutional Jurisprudence of the Federal Republic of Germany (1997) 40. Further discussion by Professor Kommers of this tradition will
} 
Now this is certainly not the place to get into philosophical debates about the nature of law, legal rules and so on, but it is certainly true to say that no-one today would consider the assumptions on which Begriffsjurisprudenz and its child, the 'step-by-step' method, are based to be an adequate description of how the law either actually is or even necessarily should be. One need only think again of the doctrine of frustration for an example of a legal concept which is a series of illustrations supported by a common theme rather than a rule that can be neatly stated as the major premise in the 'step-by-step' method's syllogistic manner. Furthermore, we all know now that rules are never entirely cut and dried, that their application can never be a value-free process, and that sometimes rules run out so that we have to resort to broader principles (if such exist), conceptions of justice, and/or our legal instinct. ${ }^{24}$ But the underlying assumption on which the 'step-by-step' method is based is that the law is a system of rules that can be simply stated as the major premise in a syllogism. This is a simplistic model of the manner in which the law works which has not been current for a hundred years or so.

\section{CONCLUSION}

Perhaps things are different in a jurisdiction, such as Germany, in which the law is codified? (I should be happier with the proposition that the law in Germany claims to be codified, as any glance at the commentaries will indicate how much case law and interpretation are required to make sense of the codes, but leave that aside.) No, there too many authors on legal methodology have long been attacking the idea that the law is a simple process of applying rules to facts. ${ }^{25}$ As Professor Karl Larenz, for example, writes, 'The assignment of a state of affairs to a category or to the area of operation of a standard in need of interpretation is not a process of syllogistic logic but a value-laden characterisation' ${ }^{26}$

be contained in Kommers, Constitutional Interpretation in Germany: Balancing Rights and Duties in Jeffrey Goldsworthy (ed.), Constitutional Interpretation: A Comparative Study (forthcoming 2006).

${ }^{24}$ Opinions differ, of course, on the degree to which such statements are true, and this author would be at the more conservative end of the spectrum; but no-one would deny that often there is a great deal of value-laden judgment involved in formulating and applying rules.

${ }^{25}$ Larenz, Methodenlehre, 166; Günter Stratenwerth/Lothar Kuhlen, Strafrecht Allgemeiner Teil ( $5^{\text {th }}$ ed; 2004) 50.

${ }^{26}$ Larenz, Methodenlehre, 275. 
This is not new or surprising, and it is not my intention to collect a large number of quotations from German authors saying similar things to commonplaces long since current in the English-speaking world as well. It is merely necessary to demonstrate that the existence of what claim to be codifications of the law does not make much difference to the degree of uncertainty involved in first ascertaining legal rules or principles and then applying them to the facts.

That process is one which the syllogistic procedure of the 'step-by-step' method conceals, because of its assumption that the law consists of rules which can be stated in a few words as the major premise in a syllogism and then automatically applied to facts in a mechanical fashion - rather than a value-laden system involving judgment (in the broadest sense of the word) as well as applying rules to facts. Its misleading conception of how the law works, even more than the vast waste of time and effort that it involves, is why it should not be foisted upon law students in this or any other country. 